\title{
Evaluating Vitamin D and foxp3 mRNA levels in women with recurrent spontaneous abortion
}

\author{
Fatemeh Dehghani Tafti ${ }^{1}$, Fateme Zare ${ }^{2}$, Seyed Mohsen Miresmaeili ${ }^{1}$, Farzaneh Fesahat ${ }^{2 *}$ \\ ${ }^{1}$ Department of Biology, Science and Arts University, Yazd, Iran \\ 2Reproductive Immunology Research Center, Shahid Sadoughi University of Medical Sciences, Yazd, Iran \\ *Corresponding author
}

\begin{abstract}
Objective: This current survey investigated the role of the Forkhead 3 box protein (foxp3) gene and serum vitamin $D$ levels in women with recurrent spontaneous abortion (RSA).

Methods: The mRNA level of the foxp3 gene in peripheral blood was evaluated in women with a history of RSA $(\mathrm{N}=40)$ and in controls $(\mathrm{N}=40)$ via quantitative polymerase chain reaction. We employed the enzymelinked immunosorbent assay to assess the serum levels of 1,25-dihydroxyvitamin D3 $(1,25(\mathrm{OH}) 2 \mathrm{D})$ in both groups. The Mann-Whitney $U$ test and Pearson's correlation coefficient were used to statistically compare study groups between and within themselves, respectively.

Results: Although mRNA levels of foxp3 were higher in women with RSA than in controls, we observed no significant change in mRNA levels of foxp3 between the two groups $(p=0.16)$. An important positive correlation was observed between foxp3 mRNA levels and 1,25(OH)2 D in controls $(p=0.003)$. In contrast, the correlation between foxp3 expression and 1,25(OH)2 D was not significant in the case group $(p=0.14)$. Serum vitamin $D$ levels were lower in women with RSA than in controls $(p<0.001)$.

Conclusions: Our findings demonstrated that 1,25Vitamin D3 along with other molecules might help prevent RSA by providing for an anti-inflammatory state not necessarily through foxp3 expression or $\mathrm{T}$ cell differentiation.
\end{abstract}

Keywords: recurrent spontaneous abortion, 1,25-dihydroxyvitamin D3, Forkhead 3 box protein

\section{INTRODUCTION}

Recurrent spontaneous abortion (RSA) refers to the recurrent loss of a fetus (bodyweight $<1000 \mathrm{~g}$ ) occurring before the $20^{\text {th }}$ week of pregnancy in more than two occasions with the same sexual partner (Practice Committee of the American Society for Reproductive Medicine, 2020). About $1-5 \%$ of all women of reproductive age suffer from RSA (Kim et al., 2004; Pildner von Steinburg \& Schneider, 2009). Early pregnancy failure is a prevalent issue accounting for $15 \%$ to $20 \%$ of known clinical pregnancies and miscarriages. (Chen \& Creinin, 2007). Numerous causes for RSA have been described, including anatomical, immune, and genetic factors (Practice Committee of the American Society for Reproductive Medicine, 2012; Motedayyen et al., 2018; Talebi et al., 2016). The cause of RSA remains unexplained in some cases (Ford \& Schust, 2009; Laird et al., 2003).

Vitamin D is a secosteroid hormone with a fundamental role in bone metabolism and mineral homeostasis as well as immune system modulation (Tamblyn et al., 2015;
Lagishetty et al., 2011). Evidence indicates that Vitamin D may be involved in the pathogenesis of RSA (Triggianese et al., 2016). Its deficiency has a remarkable impact on pregnancy outcomes and has been linked to RSA, low birth weight, poor growth, fragile ossification, and increased risk of autoimmune disorders (Tabesh et al., 2013). Indeed, several pregnancy complications including gestational diabetes, preeclampsia, maternal infection, cesarean section, and preterm labor have been considered to result from vitamin deficiency (Tabesh et al., 2013; Theodoratou et al., 2014). The extra 1 - alpha-hydroxylase activity released from the decidua, placenta, and both fetal and maternal kidneys increase the metabolism of vitamin D during pregnancy (Sanz-Salvador et al., 2015). Vitamin D affects bone metabolism more than its classic counterparts (Christakos et al., 2016; Baeke et al., 2010). There is a growing trend of reusing vitamin $D$ to reduce the regulation of pathological immune responses in patients with autoimmune or inflammatory diseases. Higher levels of vitamin D may trigger different anti-inflammatory functions, which contain the function of $\mathrm{T}$ regulatory cells (Tregs) and/or increase their numbers. Other small molecules such as niacin, short-chain fatty acids, and vitamin A may gain Tregs (Sakaki et al., 2005; Wacker \& Holick, 2013). High levels of 1,25 -dihydroxyvitamin $D 3(1,25(\mathrm{OH}) 2 \mathrm{D})$ may affect the lineage-specific foxp3 transcription factor involved in the function and creation of Tregs (Joshi et al., 2011; Jeffery et al., 2009). High levels of $1,25(\mathrm{OH}) 2 \mathrm{D}$ have been related to anti-inflammatory lymphoid polarization containing large amounts of Tregs (Dimeloe et al., 2010).

Forkhead 3 box protein (foxp3) is a nuclear transcription factor required to induce immunosuppressive activity (Hu et al., 2019). The role and function of foxp3 in tumorigenesis is conflicting. Expression of foxp3 in tumor cells plays an important role in tumorigenesis (Zuo et al., 2007a; b). Selective expression of foxp3 in human trophoblasts may be related to the multiplication and aggressive behavior of trophoblasts (Dimeloe et al., 2010). Foxp3 is known as the marker of regulatory T cells (Treg), CD4 + $\mathrm{CD} 25+$ and is a major determinant of immune function. Due to the strong immunosuppressive effect of foxp3 in Treg cells, foxp3 in trophoblasts may have immunosuppressive impacts analogous to those seen in Treg cells, and the function of Treg cells may be a new mechanism of maternal and embryonic endurance (Hu et al., 2019; Niu et al., 2011). As shown by the role of foxp3 expression in tumor cells and tumorigenesis, foxp3 may play an analogous role in trophoblasts.

However, to our knowledge, there are no reports on serum vitamin D levels and foxp3 expression patterns in women with a history of RSA. Therefore, the main goal of this prospective study was to investigate the serum concentration of vitamin D and foxp3 mRNA levels in women with a history of recurrent miscarriage compared to healthy fertile women with at least one successful pregnancy and live birth. 


\section{MATERIAL AND METHODS}

Study population and sample collection

This case-control study was based on blood samples taken from women referred to the Yazd Institute of Reproductive Sciences, Iran. The Ethics Review Board of the Science and Arts University of Yazd approved this study. Informed consent was obtained from all participants included in the study. The procedures involving humans performed during the course of the study met the ethical standards of our Institution and/or the National Research Committee and the requirements set out in the 1964 Helsinki Declaration and later amendments made thereto.

The control group consisted of 40 pregnant women without a history of miscarriage and at least one successful pregnancy. The case group included 40 women with a history of two or more cases of RSA (Maesawa et al., 2015). The groups were matched for age. A gynecologist monitored the women in the case group. No male factor etiologies, anatomical or endocrinal complications were allowed in the study; patients had normal parental chromosomal karyotypes, lack of anti-phospholipid antibodies (IgG and IgM classes), no thrombophilia, TORCH syndrome negativity, anti-cardiolipin antibodies (IgG, IgA, and IgM classes) were considered as inclusion criteria of two groups. Samples of $5 \mathrm{ml}$ of peripheral blood were taken from each study participant; half of the samples were used in gene expression evaluation and half in vitamin D level testing.

\section{Enzyme-linked immunosorbent assay}

The $2.5-\mathrm{ml}$ blood samples of each participant were separated after clotting and serum was removed. Enzyme-linked immunosorbent assay (ELISA) test kits were used to specify the serum concentrations of $1,25(\mathrm{OH}) 2 D$ in the two groups according to the manufacturer's instructions (Monokit, IRAN). The detection limit of $1,25(\mathrm{OH}) 2 D$ or each sample was $1.2 \mathrm{ng} / \mathrm{ml}$.

\section{RNA extraction and cDNA synthesis}

Two $\mathrm{ml}$ of intravenous blood samples taken from the study population were transferred to tubes containing ethylenediaminetetraacetic acid. Then, the total RNA of each sample was extracted using the easy CDNA Synthesis kit (Parstous biotechnology, Iran). The purity and concentration of extracted RNAs were determined using a spectrophotometer in the absorbance of the A260 / A280 ratio and $260 \mathrm{~nm}$, respectively (PhotoBiometer, Eppendorf, Germany). All complementary DNA (cDNA) was synthesized from $1 \mu \mathrm{g}$ RNA with the Revert Aid First Strand cDNA Synthesis Kit (parstous biotechnology, Iran). The CDNA product was kept at $-20^{\circ} \mathrm{C}$ until use.

\section{Gene expression assessment}

Quantitative real-time polymerase chain reaction (qRT-PCR) was used to determine the mRNA levels of foxp3 in case and control groups. GAPDH was considered as a reference gene for the normalization of foxp3 expression levels. The primer sequences used in this study are presented in Table1. Master Mix Green with high $\operatorname{ROX}^{\mathrm{TM}}$ (Amplicon) was utilized for PCR reaction in a StepOne system (Applied Biosystems, CA, USA). Each PCR run was performed in a final volume of $20 \mu \mathrm{L}$ containing, cDNA $(2 \mu \mathrm{L})$, forward primer $(1 \mu \mathrm{L})$, reverse primer $(1 \mu \mathrm{L})$, the master mix $(10 \mu \mathrm{L})$, and $6 \mu \mathrm{L}$ nuclease-free water. All run methods consisted of one cycle of holding stage $\left(10 \mathrm{~min}\right.$ at $\left.95^{\circ} \mathrm{C}\right)$, followed by 40 cycles in the amplification stage at $95^{\circ} \mathrm{C}$ for $15 \mathrm{~s}, 60^{\circ} \mathrm{C}$ for 30 $\mathrm{s}$, and $72^{\circ} \mathrm{C}$ for $30 \mathrm{~s}$. A melting curve stage was run after the cycling stage in the range of $60^{\circ} \mathrm{C}$ to $95^{\circ} \mathrm{C}$ to verify amplicon specificity. The relative expression level of each gene was analyzed using the $2-\Delta \Delta$ Ct method.

\section{Statistical Analysis}

SPSS 20 (Chicago, IL, USA) was used in statistical analysis. The Mann-Whitney $U$ test was applied to compare the variables between the case and control groups. Pearson's correlation coefficient was used to measure the correlation between gene expression and vitamin $D$ levels in each group. The data was presented as mean \pm standard deviation and $p<0.05$ was deemed significant.

\section{RESULTS}

A total of 40 cases and 40 healthy controls were included in this study. The demographic features of the two study groups are summarized in Table 2 . As mentioned before, women in the case group were matched in regards to age with any significant differences than those in the controls $(p \geq 0.05)$. The mRNA levels of foxp3 were higher in women with a history of RSA than in controls; however, there was no significant fold change in foxp 3 mRNA levels between patients in the case and control groups $(p=0.16$, Mean \pm SEM: $16.87 \pm 13.11$ vs. $5.26 \pm 1.39$, respectively) (Figure 1 ). There was a significant direct correlation between foxp3 expression and $1,25(\mathrm{OH}) 2 D$ in controls $(p=0.003, \mathrm{R}=0.49)$. In contrast, the correlation between foxp3 gene expression and $1,25(\mathrm{OH}) 2 D$ levels was not significant in the case group $(p=0.14, \mathrm{R}=-0.25)$ (Table $3) .1,25(\mathrm{OH}) 2 D$ levels were significantly lower in the serum samples of women with a history of RSA compared to controls $(p<0.001$, Mean \pm SEM: $21.39 \pm 1.94$ versus $36.84 \pm 3.97$, respectively) (Figure 2 ).

Table 1. Primer sequences used for the real-time polymerase chain reaction.

\begin{tabular}{|l|l|l|l|}
\hline Gene & sequence (5'-3') & Accession No. & PCR product (bp) \\
\hline \multirow{2}{*}{ oxp3 } & F: ACC TGG AAG AAC GCC ATC & NM_014009.4 & 192 \\
\hline \multirow{2}{*}{ GAPDH } & $\begin{array}{l}\text { F: AAT TCG TCC ATC CTC CTT TC } \\
\text { R:GCA GAG ATG ATG ACC CTT TTG }\end{array}$ & NM_001357943.2 & 118 \\
\hline
\end{tabular}

PCR, polymerase chain reaction; F, forward; R, reverse; Foxp3, forkhead box P3; GAPDH, glyceraldehyde-3-phosphate dehydrogenase

Table 2. Demographic data of the study groups.

\begin{tabular}{|l|c|c|c|}
\hline Groups & Age (Year) & Number of miscarriages & Successful pregnancies \\
\hline Case $(\mathbf{N}=\mathbf{4 0})$ & $31 \pm 3.78$ & $4.0 \pm 0.9$ & 0 \\
\hline Control $(\mathbf{N}=\mathbf{4 0})$ & $31.06 \pm 3.43$ & 0 & $2.12 \pm 0.93$ \\
\hline
\end{tabular}

Data are presented as mean \pm S.D.

Case; Recurrent spontaneous abortion, Control; Healthy fertile women 


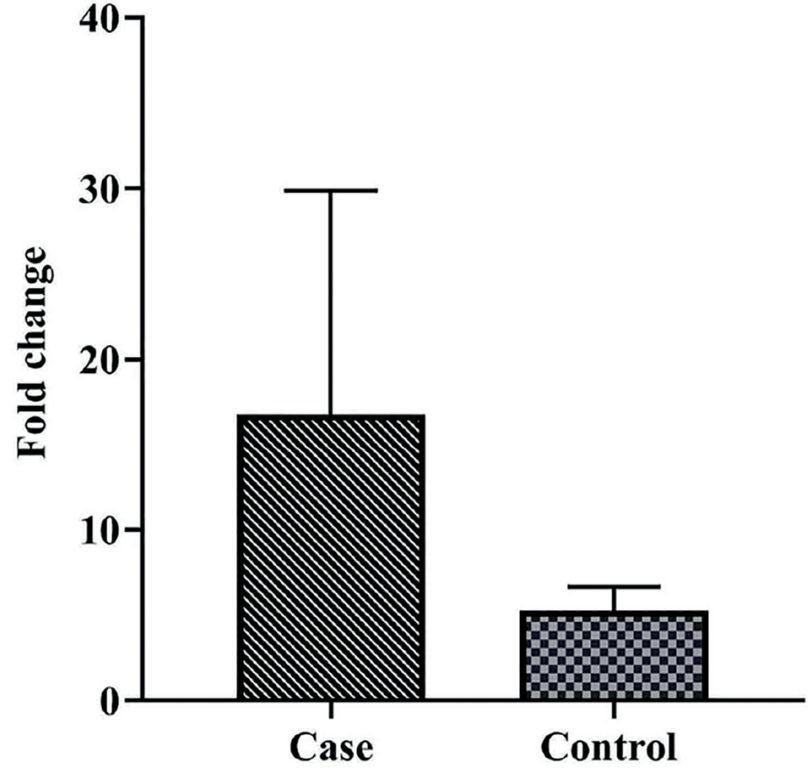

Figure 1. Comparison of foxp3 gene expression in cells obtained from blood samples of women with a history of recurrent spontaneous abortion (case) and healthy fertile women (controls) There was no significant fold change in foxp 3 mRNA levels between case and control groups ( $p$ value $=0.16$, Mean \pm SEM: $16.87 \pm 13.11$ versus $5.26 \pm 1.39$, respectively).

\section{DISCUSSION}

The cause of RSA, a negative pregnancy outcome that occurs in women around the world, is related to endocrine abnormalities, thrombophilic disorders, genetic factors, and anatomical abnormalities. However, the causes of most cases of RSA are unknown and may relate to immune factors (Wolf et al., 2005).

Poor vitamin $D$ levels have been associated with pregnancy loss, recurrent implantation failure, and pregnancy-related disorders such as preeclampsia (Schröder-Heurich et al., 2020). This study found significantly lower concentrations of vitamin $D$ in the blood serum samples of patients with a history of RSA compared to controls. Li et al. (2017) assessed the concentration of vitamin D and the expression of vitamin $D$ receptors in the decidual tissues of women with a history of RSA $(\mathrm{N}=30)$ and women in early pregnancy undergoing elective abortion as controls $(\mathrm{N}=30)$. As seen in our study, individuals with a history of RSA had significantly lower levels of vitamin D and its receptor in deciduous tissues compared to controls, indicating that vitamin $D$ has a role in the production of inflammatory cytokines and possibly in the etiology of RSA (Li et al., 2017). Sharif et al. (2018) assessed the relationship between vitamin $D$, recurrent pregnancy loss, and

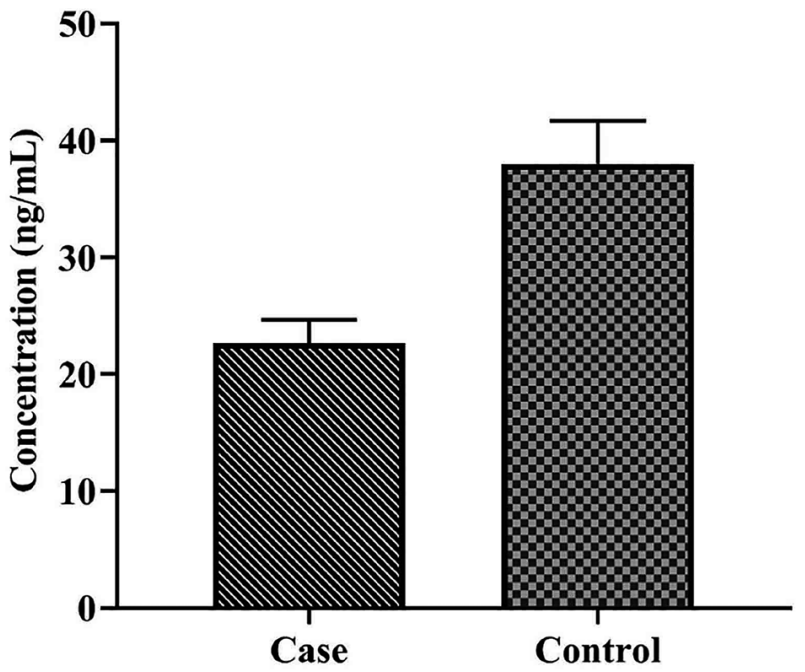

Figure 2. Comparison of vitamin $D$ in serum from blood samples of women with a history of recurrent spontaneous abortion (case) and healthy fertile women (controls) There was a significantly lower level of vitamin $D$ in the serum samples of case group subjects compared to controls ( $p$ value $\leq 0.001$, Mean \pm SEM: $21.39 \pm 1.94$ versus $36.84 \pm 3.97$, respectively).

autoimmunity. According to the authors, during pregnancy, fetal endurance can occur through a complex interaction of various regulatory factors in the innate and adaptive immune system, which can result in miscarriage. While deficiency has been associated with pregnancy failure, vitamin $D$ may modulate the immune response of the fetal interface and help create a more conducive environment for a successful pregnancy. The authors suggested a significant role for adequate vitamin $D$ supplementation in preventing recurrent miscarriage (Sharif et al., 2018). Two reviews conducted by Gonçalves et al. (2018) and Zhang et al. (2017) concluded that vitamin D might be essential in the immune system, promoting implantation and successful pregnancy. Also, women with a history of RSA with low levels of vitamin $D$ appear to have more autoimmune and cellular immune abnormalities.

Lack of Vitamin D suggests that pre-pregnancy vitamin D supplementation in women may affect glucose-induced tumor necrosis factor receptors such as foxp 3 and glucocorticoid receptors protect against RSA (Abdollahi et al., 2020a). One research showed that foxp3 was also expressed in human trophoblasts in addition to Treg cells and abnormal expression of foxp 3 in trophoblasts may relate to RPL (Hu et al., 2019). Hu et al. (2019) used RT-qPCR to study the foxp3 expression profile in the trophoblasts of women with recurrent pregnancy loss. They concluded that foxp3 is expressed in trophoblasts and is reduced in recurrent pregnancies. Thus, regulation of foxp 3 may

Table 3. Correlation between Vitamin D and FOXP3 expression in case and control groups.

\begin{tabular}{|c|c|c|}
\hline Groups & Variable & FOXP3 expression \\
\hline Case & \multirow{2}{*}{ Vitamin D } & $\begin{array}{c}R=-0.25 \\
P=0.14 \\
C I=-.0 .53--0.08\end{array}$ \\
\hline Control & & $\begin{array}{c}\mathrm{R}=0.49 \\
\mathbf{P}=\mathbf{0 . 0 0 3} \\
\mathrm{CI}=0.18-0.7\end{array}$ \\
\hline
\end{tabular}

Foxp3, forkhead box P3. Pearson's correlation coefficient was used. 
help maintain maternal tolerance and fetal growth (Hu et al., 2019). Selective expression of foxp 3 in human trophoblasts suggests that foxp3 expression may be associated with aggressive behavior of trophoblasts and proliferation. Abdollahi et al. (2020b) reported an increase in foxp3 gene expression in the peripheral blood mononuclear cells (PBMCs) of women with unexplained recurrent pregnancy loss (URPL) in the presence of vitamin D3 compared to untreated PBMCs. In contrast, there was no significant change in the control group regarding foxp3 gene expression in the PBMCs in the presence of 1,25Vitamin D3 compared to untreated PBMCs. They also showed that foxp3 gene expression decreased significantly in PBMCs in women with URPL compared to controls (Abdollahi et al., 2020b). Unlike the abovementioned studies, in this study, the level of foxp3 mRNA was increased in the blood of women with a history of RSA compared to controls, albeit not significantly. Also, we detected no significant direct correlation between 1,25 Vitamin D3 concentrations and foxp3 expression in the case group. Despite the enhanced foxp3 expression in CD4+ $T$ cells by $1,25(\mathrm{OH}) 2 \mathrm{D}$ and the capacity of this vitamin to regulate gene expression via direct binding to the genes, it is unknown whether $1,25(\mathrm{OH}) 2 \mathrm{D} 3$ may directly induce foxp3 gene expression without involving other molecules (Kang et al., 2012). Based on the findings of this study, 1,25 (OH) 2VD3 may, along with other molecules, alter foxp3 expression (Kang et al., 2012).

In in-vitro cultures of human $\mathrm{CD} 4+\mathrm{CD} 25-\mathrm{T}$ cells and plain putative $\mathrm{T}$ cells, $1,25(\mathrm{OH}) 2 \mathrm{D} 3$ was reported to increase the frequency of activation-induced foxp3 $+\mathrm{T}$ cells, depending on the presence of IL-2 (20). However, a comparative study using naive mouse $T$ cells showed that 1,25- $(\mathrm{OH}) 2 \mathrm{D} 3$ inhibited both IL-17 and Treg differentiation in vitro (Chang et al., 2010).

In conclusion, our findings demonstrated that $1,25 \mathrm{Vi}-$ tamin D3 along with other molecules might act to prevent RSA by providing an anti-inflammatory state not necessarily through foxp3 expression and T cell differentiation.

\section{Author contributions}

Contribution of each author made to the manuscript included: (1) Conception and design: F.D.T, S.M.M., F.Z., F.F., (2) Administrative support: F.F., F.Z, (3) Provision of study material or patients: F.D.T., S.M.M., F.F., F.Z., (4) Data collection and treatment: F.F., F.Z., F.D.T., (5) Data analysis and interpretation: S.M.M., F.D.T., F.F., (6) Manuscript writing: All authors.

\section{Funding sources}

Owner funds were used in this study.

\section{CONFLICTS OF INTEREST}

The authors have no conflict of interest to declare.

\section{Corresponding author:}

Farzaneh Fesahat

Assistant Professor in Reproductive Biology

Reproductive Immunology Research Center

Shahid Sadoughi University of Medical Sciences

Yazd, Iran.

E-mail: farzaneh.fesahat@gmail.com

\section{REFERENCES}

Abdollahi E, Saghafi N, Rezaee SA, Rastin M, Jarahi L, Clifton $\mathrm{V}$, Rafatpanah $\mathrm{H}$. Evaluation of 1,25(OH)2D3 Effects on FOXP3, ROR-yt, GITR, and CTLA-4 Gene Expression in the PBMCs of Vitamin D-Deficient Women with Unexplained Recurrent Pregnancy Loss (URPL). Iran Biomed J. 2020a;24:295305. PMID: 32429643 DOI: 10.29252/ibj.24.5.290
Abdollahi E, Rezaee SA, Saghafi N, Rastin M, Clifton V, Sahebkar A, Rafatpanah $\mathrm{H}$. Evaluation of the Effects of 1,25 Vitamin D3 on Regulatory T Cells and T Helper 17 Cells in Vitamin D-deficient Women with Unexplained Recurrent Pregnancy Loss. Curr Mol Pharmacol. 2020b;13:306-17. PMID: 32124705 DOI: $10.2174 / 18744672136662003031$ 30153

Baeke F, Takiishi T, Korf H, Gysemans C, Mathieu C. Vitamin D: modulator of the immune system. Curr Opin Pharmacol. 2010;10:482-96. PMID: 20427238 DOI: 10.1016/j. coph.2010.04.001

Chang JH, Cha HR, Lee DS, Seo KY, Kweon MN. 1,25-Dihydroxyvitamin D3 inhibits the differentiation and migration of $\mathrm{T}(\mathrm{H}) 17$ cells to protect against experimental autoimmune encephalomyelitis. PLoS One. 2010;5:e12925. PMID: 20886077 DOI: 10.1371/journal.pone.0012925

Chen BA, Creinin MD. Contemporary management of early pregnancy failure. Clin Obstet Gynecol. 2007;50:67-88. PMID: 17304025 DOI: 10.1097/GRF.0b013e31802f1233

Christakos S, Dhawan P, Verstuyf A, Verlinden L, Carmeliet G. Vitamin D: Metabolism, Molecular Mechanism of Action, and Pleiotropic Effects. Physiol Rev. 2016;96:365-408. PMID: 26681795 DOI: 10.1152/physrev.00014.2015

Dimeloe S, Nanzer A, Ryanna K, Hawrylowicz C. Regulatory $T$ cells, inflammation and the allergic response-The role of glucocorticoids and Vitamin D. J Steroid Biochem Mol Biol. 2010;120:86-95. PMID: 20227496 DOI: 10.1016/j. jsbmb.2010.02.029

Ford HB, Schust DJ. Recurrent pregnancy loss: etiology, diagnosis, and therapy. Rev Obstet Gynecol. 2009;2:7683. PMID: 19609401

Gonçalves DR, Braga A, Braga J, Marinho A. Recurrent pregnancy loss and vitamin $D$ : A review of the literature. Am J Reprod Immunol. 2018;80:e13022. PMID: 30051540 DOI: $10.1111 /$ aji.13022

Hu X, Wang Y, Mor G, Liao A. Forkhead box P3 is selectively expressed in human trophoblasts and decreased in recurrent pregnancy loss. Placenta. 2019;81:1-8. PMID: 31138426 DOI: $10.1016 /$ j.placenta.2019.04.003

Jeffery LE, Burke F, Mura M, Zheng Y, Qureshi OS, Hewison M, Walker LS, Lammas DA, Raza K, Sansom DM. 1,25-Dihydroxyvitamin D3 and IL-2 combine to inhibit T cell production of inflammatory cytokines and promote development of regulatory $T$ cells expressing CTLA-4 and FoxP3. J Immunol. 2009;183:5458-67. PMID: 19843932 DOI: 10.4049/jimmunol.0803217

Joshi S, Pantalena LC, Liu XK, Gaffen SL, Liu H, Rohowsky-Kochan C, Ichiyama K, Yoshimura A, Steinman L, Christakos S, Youssef S. 1,25-dihydroxyvitamin D(3) ameliorates Th17 autoimmunity via transcriptional modulation of interleukin-17A. Mol Cell Biol. 2011;31:3653-69. PMID: 21746882 DOI: $10.1128 /$ MCB.05020-11

Kang SW, Kim SH, Lee N, Lee WW, Hwang KA, Shin MS, Lee SH, Kim WU, Kang I. 1,25-Dihyroxyvitamin D3 promotes FOXP3 expression via binding to vitamin $D$ response elements in its conserved noncoding sequence region. J Immunol. 2012;188:5276-82. PMID: 22529297 DOI: 10.4049/jimmunol.1101211 
Kim JW, Park SY, Kim YM, Kim JM, Han JY, Ryu HM. X-chromosome inactivation patterns in Korean women with idiopathic recurrent spontaneous abortion. J Korean Med Sci. 2004;19:258-62. PMID: 15082900 DOI: 10.3346/ jkms.2004.19.2.258

Lagishetty V, Liu NQ, Hewison M. Vitamin D metabolism and innate immunity. Mol Cell Endocrinol. 2011;347:97105. PMID: 21664425 DOI: 10.1016/j.mce.2011.04.015

Laird SM, Tuckerman EM, Cork BA, Linjawi S, Blakemore AI, $\mathrm{Li}$ TC. A review of immune cells and molecules in women with recurrent miscarriage. Hum Reprod Update. 2003;9:163-74. PMID: 12751778 DOI: 10.1093/humupd/dmg013

Li N, Wu HM, Hang F, Zhang YS, Li MJ. Women with recurrent spontaneous abortion have decreased $25(\mathrm{OH})$ vitamin $\mathrm{D}$ and VDR at the fetal-maternal interface. Braz J Med Biol Res. 2017;50:e6527. DOI: 10.1590/1414-431x20176527

Maesawa Y, Yamada H, Deguchi M, Ebina Y. History of biochemical pregnancy was associated with the subsequent reproductive failure among women with recurrent spontaneous abortion. Gynecol Endocrinol. 2015;31:306-8. PMID: 25539407 DOI: 10.3109/09513590.2014.994601

Motedayyen H, Zarnani AH, Tajik N, Ghotloo S, Rezaei A. Immunomodulatory effects of human amniotic epithelial cells on naive CD4+ T cells from women with unexplained recurrent spontaneous abortion. Placenta. 2018;71:31-40. PMID: 30415745 DOI: 10.1016/j.placenta.2018.06.008

Niu J, Jiang C, Li C, Liu L, Li K, Jian Z, Gao T. Foxp3 expression in melanoma cells as a possible mechanism of resistance to immune destruction. Cancer Immunol Immunother. 2011;60:1109-18. PMID: 21547596 DOI: 10.1007/ s00262-011-1025-3

Pildner von Steinburg S, Schneider KTM. Recurrent spontaneous abortions-an update on diagnosis and management. ] Reproduktionsmed Endokrinol. 2009;6:11-6.

Practice Committee of the American Society for Reproductive Medicine. Evaluation and treatment of recurrent pregnancy loss: a committee opinion. Fertil Steril. 2012;98:1103-11. PMID: 22835448 DOI: 10.1016/j.fertnstert.2012.06.048

Practice Committee of the American Society for Reproductive Medicine. Electronic address: asrm@asrm.org. Definitions of infertility and recurrent pregnancy loss: a committee opinion. Fertil Steril. 2020;113:533-5. PMID: 32115183 DOI: 10.1016/j.fertnstert.2019.11.025

Sakaki T, Kagawa N, Yamamoto K, Inouye K. Metabolism of vitamin D3 by cytochromes P450. Front Biosci. 2005;10:119-34. PMID: 15574355 DOI: 10.2741/1514

Sanz-Salvador L, García-Pérez MÁ, Tarín JJ, Cano A. Bone metabolic changes during pregnancy: a period of vulnerability to osteoporosis and fracture. Eur J Endocrinol. 2015;172:R5365. PMID: 25209679 DOI: 10.1530/EJE-14-0424

Schröder-Heurich B, Springer CJP, von Versen-Höynck F. Vitamin D Effects on the Immune System from Periconception through Pregnancy. Nutrients. 2020;12:1432. PMID: 32429162 DOI: $10.3390 /$ nu12051432
Sharif K, Sharif Y, Watad A, Yavne Y, Lichtbroun B, Bragazzi $\mathrm{NL}$, Amital $\mathrm{H}$, Shoenfeld $Y$. Vitamin $D$, autoimmunity and recurrent pregnancy loss: More than an association. Am J Reprod Immunol. 2018;80:e12991. PMID: 29923244 DOI: 10.1111/aji.12991

Tabesh M, Salehi-Abargouei A, Tabesh M, Esmaillzadeh A. Maternal vitamin $D$ status and risk of pre-eclampsia: a systematic review and meta-analysis. J Clin Endocrinol Metab. 2013;98:3165-73. PMID: 23783101 DOI: 10.1210/ jc. 2013-1257

Talebi AR, Fesahat F, Mangoli E, Ghasemzadeh J, Nayeri $M$, Sadeghian-Nodoshan F. Relationship between sperm protamine deficiency and apoptosis in couples with unexplained repeated spontaneous abortions. Int J Reprod Biomed. 2016;14:199-204. PMID: 27294219 DOI: 10.29252/ijrm.14.3.199

Tamblyn JA, Hewison M, Wagner CL, Bulmer JN, Kilby MD. Immunological role of vitamin $D$ at the maternal-fetal interface. J Endocrinol. 2015;224:R107-21. PMID: 25663707 DOI: $10.1530 / J O E-14-0642$

Theodoratou E, Tzoulaki I, Zgaga L, Ioannidis JP. Vitamin $D$ and multiple health outcomes: umbrella review of systematic reviews and meta-analyses of observational studies and randomised trials. BMJ. 2014;348:g2035. PMID: 24690624 DOI: $10.1136 /$ bmj.g2035

Triggianese P, Perricone C, Chimenti MS, De Carolis C, Perricone R. Innate Immune System at the Maternal-Fetal Interface: Mechanisms of Disease and Targets of Therapy in Pregnancy Syndromes. Am J Reprod Immunol. 2016;76:245-57. PMID: 27108670 DOI: 10.1111/ aji.12509

Wacker M, Holick MF. Sunlight and Vitamin D: A global perspective for health. Dermatoendocrinol. 2013;5:51-108. PMID: 24494042 DOI: 10.4161/derm.24494

Wolf $D$, Wolf $A M$, Rumpold $H$, Fiegl $H$, Zeimet AG, MullerHolzner E, Deibl M, Gastl G, Gunsilius E, Marth C. The expression of the regulatory $T$ cell-specific forkhead box transcription factor FoxP3 is associated with poor prognosis in ovarian cancer. Clin Cancer Res. 2005;11:8326-31. PMID: 16322292 DOI: $10.1158 / 1078-0432$.CCR-05-1244

Zhang $H$, Huang $Z$, Xiao L, Jiang $X$, Chen D, Wei Y. Meta-analysis of the effect of the maternal vitamin $D$ level on the risk of spontaneous pregnancy loss. Int J Gynaecol Obstet. 2017;138:242-9. PMID: 28500757 DOI: 10.1002/ ijgo.12209

Zuo $T$, Liu R, Zhang $H$, Chang $X$, Liu $Y$, Wang $L$, Zheng $P$, Liu $Y$. FOXP3 is a novel transcriptional repressor for the breast cancer oncogene SKP2. J Clin Invest. 2007a;117:3765-73. PMID: 16322292 DOI: $10.1172 / J C I 32538$

Zuo T, Wang L, Morrison C, Chang $X$, Zhang $\mathrm{H}$, Li W, Liu $\mathrm{Y}_{\text {, }}$ Wang Y, Liu X, Chan MW, Liu JQ, Love R, Liu CG, Godfrey $V$, Shen $R$, Huang $T H$, Yang $T$, Park BK, Wang $C Y$, Zheng $\mathrm{P}$, et al. FOXP3 is an X-linked breast cancer suppressor gene and an important repressor of the HER-2/ErbB2 oncogene. Cell. 2007b;129:1275-86. PMID: 17570480 DOI: $10.1016 /$ j.cell.2007.04.034 